\title{
NORMAL STANDARDS OF GASTRIC FUNCTION
}

By W. SCOTT POLLAND AND ARTHUR L. BLOOMFIELD

(From the Department of Medicine, Stanford University Medical School, San Francisco)

(Received for publication July 15, 1930)

The establishment of normal standards of gastric function is a prerequisite to the recognition of abnormal conditions. Such standards have heretofore been inadequate, with the result that studies of stomach secretion have fallen into disfavor in the clinic. As we pointed out in a previous paper (1), a test of function must be based on certain general criteria: (1) the test must be applied under standard conditions, (2) it must impose a load on the function under consideration, (3) it must be capable of identical repetition and (4) it must actually yield information which experience shows to be useful. Reasons why the gastric test-meals in ordinary use are unsatisfactory were also exposed (1), and it was pointed out that measurement of the volume and acidity of the pure gastric juice, after stimulation by histamine, constituted the most fruitful clinical procedure at present available for studying the secretory function of the stomach. The technique of the method was described, and it was shown that if the total gastric juice is collected over successive ten-minute periods after stimulation, the greatest quantity is usually produced in the twenty to thirty minute period, and the acidity usually reaches a maximum at this time (2). These two values, therefore, the greatest tenminute secretory volume and the highest acidity attained, make up the essential elements in an assay of the secretory capability of a given stomach under definite conditions.

Determination of these factors in an adequate series of normal people would furnish data with which deviations in disease might properly be compared and from which useful conclusions could be drawn. Some years ago an attempt was made to set up standards along these lines on the basis of data obtained by alcohol test meals $(3,4)$. While useful information was obtained there were, as a result of the inadequacy of alcohol as a stimulus to gastric secretion, some errors which 
have since been recognized; in brief, a good many "normal" people who failed to secrete acid have since been shown to be capable of doing so by the application of histamine. Hence the erroneous conclusion was drawn that gastric acidity is much lower in the old than in the young, a finding which the present observations have modified. The conclusion that, on the whole, volume of secretion lessens considerably with age is however sustained, as will be pointed out below.

\section{MATERIAL}

The selection of the normal people, who were to serve as subjects for the derivation of standards, immediately presented a serious problem. It seemed proper that the selection should be made before the test was carried out, and we promptly encountered the difficulty of finding people who had always been entirely free of digestive symptoms. However, such a series was assembled and the tests were carried out; but despite the absence of any historical or physical evidence of gastric disorder, it became evident, on the basis of the secretory studies, that some of the subjects did not possess normal stomachs. This was especially so of certain individuals who failed to secrete acid, or secreted it only in minimal amounts, after histamine stimulation. The exact significance of such findings is not clear, but in view of the presumption that an organic lesion of the mucosa must exist in these cases they were arbitrarily discarded from the series. This subject will be discussed in another paper. In brief, then, people who had no digestive symptoms, and who secreted a juice with free hydrochloric acid of over 10 were considered normal. It also seemed undesirable to base the standards on findings in any highly selected group such as medical students, with whom one could not fairly compare the miscellaneous run of people of all ages seen in medical practice. We used, therefore, hospital patients provided the above specifications were fulfilled and provided there was no acute, febrile or cachectic condition or any disorder which presumably might disturb gastric function such as cardiac decompensation.

\section{METHODS}

The test procedure has already been outlined $(1,2)$. Briefly, a small tube was introduced into the stomach under fasting basal con- 
ditions. After the fasting juice had been withdrawn $0.1 \mathrm{mgm}$. of histamine (ergamine) per $10 \mathrm{kgm}$. of body weight was injected hypodermically. The total secretions were then aspirated over successive ten-minute periods until the flow of juice subsided to the basal level (usually one hour). The greatest ten-minute volume of secretion

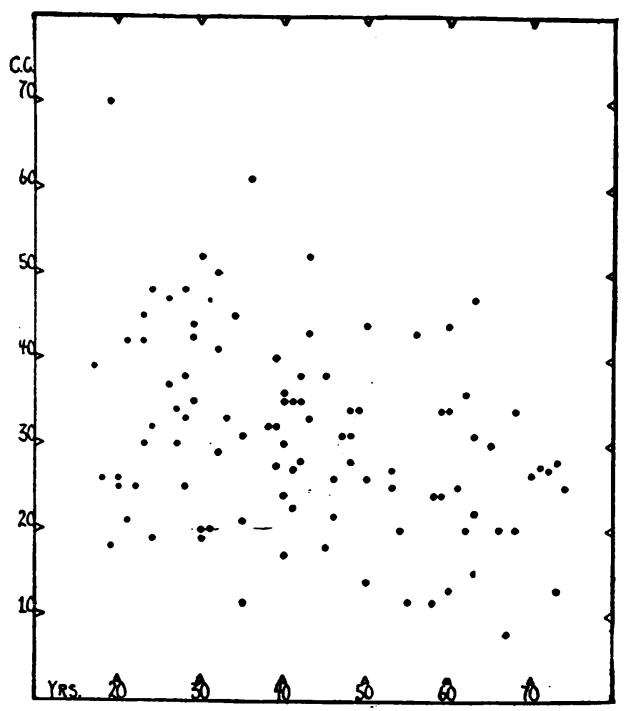

Chart 1. Highest Ten-Minute Secretory Volume in Each Case (cc.) Plotted Against Age of Subject

and the highest titratable acidity attained were considered indices of stomach function, and they furnish the data which are herewith reported.

\section{RESULTS}

Volume of secretion. In chart 1 each dot represents the greatest ten-minute volume of gastric secretion, after histamine stimulation, in a different person. The wide variations are striking, and make it evident that no very narrow standards of normality can be set up. However, as shown by the distribution curve ${ }^{1}$ (chart 2), about one-

${ }^{1}$ No attempt has been made to subject the material to accurate mathematical analysis. It is evident, however, that the distribution of secretory volumes approaches a normal curve whereas the distribution curve of acidity is skewed (chart 5). 
half of the determinations fell within the limits of 21 to $35 \mathrm{cc}$. We have made no attempt to correlate the findings with any special habitus or type of person, except in so far as age has been considered, and a further inspection of chart 1 shows that most of the larger volumes are found in young people whereas the smaller volumes are mainly from those over fifty years of age. If one averages the secretory volumes for the various decades, the fact that less gastric juice is

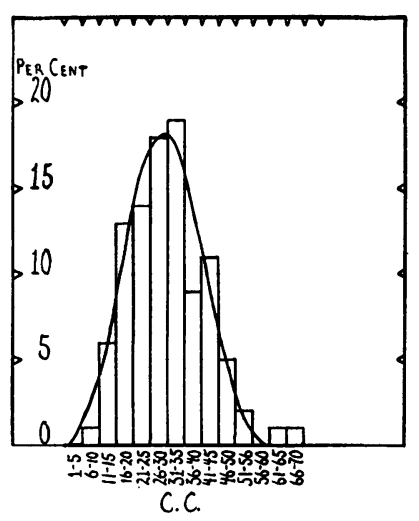

Chart 2

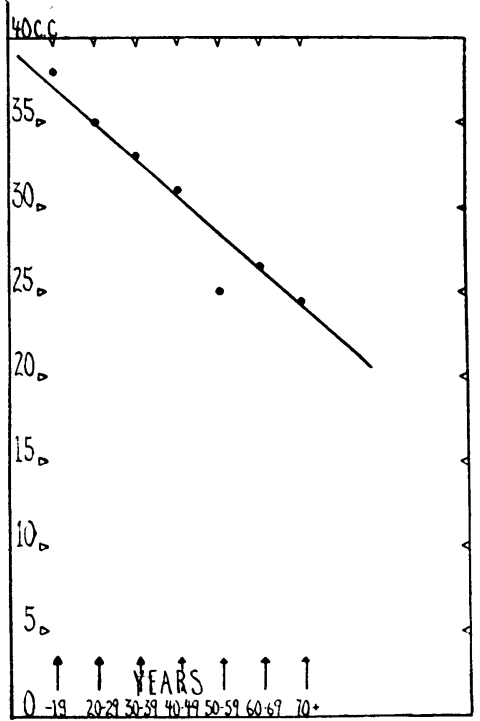

CharT 3

Chart 2. Histogram and Smoothed Curve of Distribution of Volume of SeCRETion in ENTIRE Group

Chart 3. Average Maximum Ten-Minute Secretory Volume in Various Decades

secreted with advancing age becomes quite evident. The figures are graphically shown in chart 3. The explanation of this fact is still in doubt: whether there is a "physiological" deterioration of function, as people grow older, or whether the lessened secretion is the reflection of multiple focal injuries over a period of years, whereby secreting cells here and there have been damaged, can not be stated. The solution of the problem awaits histological study of stomachs 


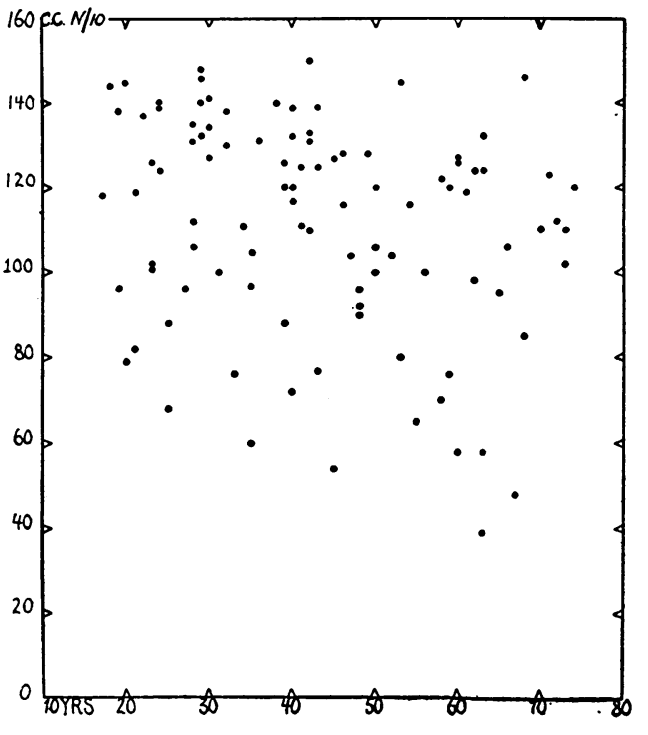

Chart 4

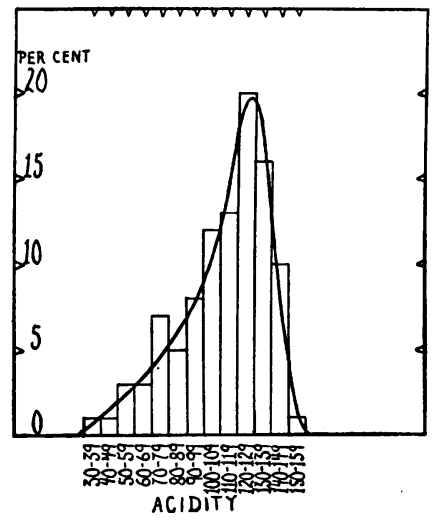

Chart 5

Chart 4. Highest Titratable (Total) Acid in each Case Plotted Against Age of SUbJect

Chart 5. Histogram and Smoothed Curve of Distribution of Acidity in ENTIRE GROUP

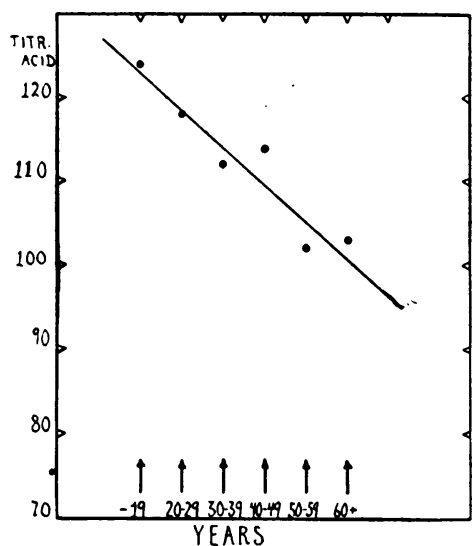

Chart 6

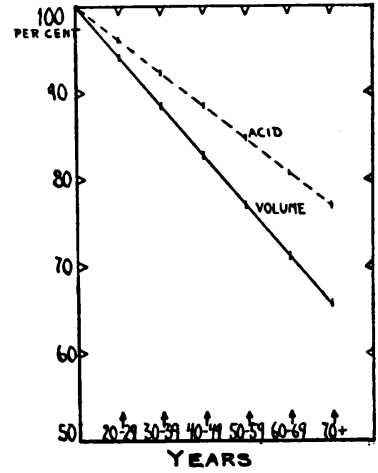

Chart 7

Chart 6. Average Maximum Acidity in Various Decades Chart 7. Percentage Decrease in Volume and Acid With Advancing 
whose function has been tested during life, and it is obviously difficult to obtain the necessary material where healthy people are concerned.

\section{ACIDITY}

In chart 4 the highest titratable acidity in each subject is shown. Here, as with volume of secretion, considerable variation is evident,

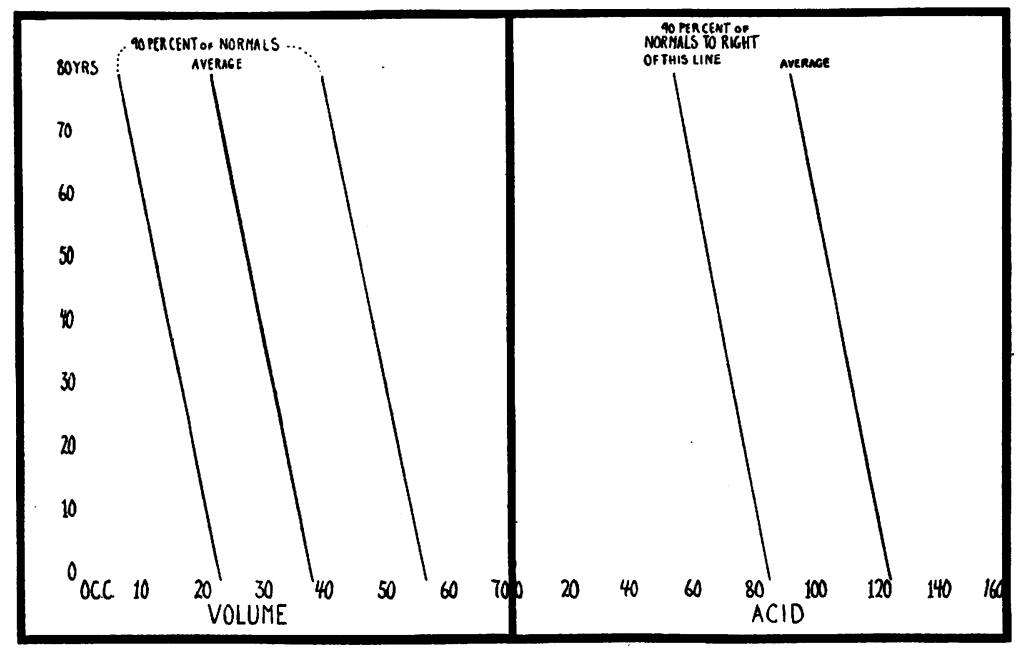

Chart 8. Chart for Making Clinical Report of Acidity and Volume of Gastric SeCRETION

From a statistical standpoint it would be preferable to have a series of vertical lines representing sigma or probable error, but in view of the small number of cases in each class this was not attempted. It should also be noted that we have no observation in the age periods below 15 years and that the average lines are therefore probably inaccurate for these periods. The chart should be used only to record observations made on adults.

but the distribution curve (chart 5) is of different form. The frequency of the lower values gradually rises to be followed by a rapid increase above 90 to a peak, in the vicinity of 135 , after which there is an abrupt descent; three fourths of the values lie above 100. There is evidently an upper level of concentration of acid in the vicinity of 150 , which the normal stomach is incapable of surpassing, but under 
the powerful influence of histamine this value is often approached. A definite lowering of the acid values with advancing age is seen when the figures in various decades are averaged. The figures (chart 6) are not as striking as in the case of volume of secretion but are none the less definite. The explanation here also is not at hand. In chart 7 the percentage decline in volume and acidity is shown simultaneously, the values in the youngest age period being taken as 100 per cent.

\section{DISCUSSION}

As we pointed out above, one of the main objects of these observations was to set standards with which findings in gastric disorders could properly be compared. Are there, for example, in cancer, in ulcer, in gastritis and in other diseases secretory findings which deviate in a characteristic way from the normal, so that practical diagnostic conclusions can be drawn? A glance at the distribution curves makes it evident that no exclusive findings are likely to be obtained; and, as is true of many similar problems in medicine, the matter resolves itself into a question of frequencies. In other words, if certain data are obtained from an instance of a gastric disorder, it will usually be difficult to say more than that such findings may be expected in a given percentage of normal people; the further the findings deviate from the normal distribution curve, the more likely they are to be indicative of abnormal conditions, and it is only by assembling large groups of cases that an approximate understanding of their clinical significance will be obtained. On this basis, as we have already pointed out elsewhere (1), useful practical information has been obtained bearing on the differentiation of ulcer and of cancer of the stomach. The following charts are suggested as the most illuminating means of reporting observations on gastric function in the Clinic (chart 8). If, in the case under consideration, the values for acid and volume are marked on such a chart, the relations of the findings to the normal may be visualized. The physician may then make his interpretation together with the clinical data as a whole.

In conclusion, it should be emphasized, that all of the present work has been done on adults. There is reason to believe that conditions may be quite different in children, and especially in infants. 


\section{BIBLIOGRAPHY}

1. Bloomfield, A. L., and Polland, W. S., J. Am. Med. Assoc., 1929, xcii, 1508. The Diagnostic Value of Studies of Gastric Secretion.

2. Polland, W. S., Roberts, A. M., and Bloomfield, A. L., J. Clin. Invest., 1928, v, 611. The Chloride, Base and Nitrogen Content of Gastric Juice, after Histamine Stimulation.

3. Bloomfield, A. L., and Keefer, C. S., J. Clin. Invest., 1928, v, 295. Gastric Motility and the Volume of Gastric Secretion in Man.

4. Ibid., J. Clin. Invest., 1928, v, 285. Gastric Acidity: Relation to Various Factors Such as Age and Physical Fitness. 